\title{
Synthesis, X-ray Characterisation, Hirshfeld Surface and Theoretical Studies of A Novel Cd(II) Coordination Compound Bearing 2,3- Pyridinedicarboxylic Acid
}

\section{Sarra Soudani ( $\nabla$ sarrasoudani@yahoo.fr)}

Université de Carthage

Kamel Kaabi

Université de Carthage

Christian Jelsch

Université de Lorraine

Jin Xiao Mi

Xiamen University

Frédéric Lefebvre

Laboratoire de Chimie Organométallique de Surface (LCOMS), Ecole Supérieure de Chimie Physique Electronique

Cherif Ben Nasr

Université de Carthage

\section{Research Article}

Keywords: Cd(II) coordination compound, enrichment ratio, electrostatic energy, 2,3-pyridinedicarboxylate ligand, DFT

Posted Date: May 5th, 2021

DOl: https://doi.org/10.21203/rs.3.rs-475047/v1

License: (c) (i) This work is licensed under a Creative Commons Attribution 4.0 International License. Read Full License 


\section{Abstract}

A new compound of cadmium (II), [(Cd(2,3-pdcH $\left.\left.)_{3}\right)\left(\mathrm{Cd}\left(\mathrm{H}_{2} \mathrm{O}\right)_{6}\right)\right]$, has been synthesized by reaction of 2,3pyridine dicarboxylic anhydride with cadmium dichloride. The title compound has been characterized by X-ray crystallography and theoretical chemistry calculations. The new coordinated compound crystallizes in the trigonal space group $P 3$. Its crystal structure consists of two homoleptic cadmium species which are showing a distorted octahedral geometry, one with six water molecules and the other one with three organic ligands coordinated to cadmium by the nitrogen atom of the pyridine ring and one oxygen atom from the deprotonated dicarboxylic acid group. The different intermolecular interactions were defined by Hirshfeld surface analyses and described in terms of electrostatic energy. $\mathrm{O}-\mathrm{H}$... O hydrogen bonds between the water molecules and the carboxylate groups are formed and stabilized the crystal packing. Also, hydrophobic contacts consist between the pyridine cycle and the carboxylic/carboxylate functions. The HOMO and LUMO orbitals and the Molecular Electrostatic Potential maps were performed by the use of DFT theoretical calculations.

\section{Introduction}

Cadmium coordination compounds and pyridine dicarboxylic acids are well- known and are intensively studied due to their role and their large potential applications in inorganic biochemistry fields $[1,2]$. Different structures of the $\mathrm{Cd}(\mathrm{II})$ complexes are based on the variety of coordination geometries which can be achieved by a $\mathrm{d}^{10}$ metal ion, such as e.g. tetrahedral, trigonal bipyramidal, square pyramidal, octahedral and also distorted polyhedral [3]. Recently, transition metal compounds have received an important attention due to their particular properties which can be tuned by changing the organic ligands. In fact, pyridine dicarboxylic acids are able to form coordination polymers with transition metals and can be considered as as polydentate ligands in coordination chemistry through the nitrogen atom and the oxygen atom of carboxylic group $[4,5]$. They can act in a mono or a double deprotonated form to generate with metals versatile structural motifs and extended supra molecular structures by selfassembling of metal-organic units via hydrogen bonds and $p-p$ interactions with various architectures, topologies and various coordination modes [6-9]. Pyridine dicarboxylic acids are found in the metabolic pathways of animals and they are used for the transport and scavenging of metal ions by the body. It is also reported that this ligand is used to develop more effective anti HIV agents [10-12] and it is well known for its important biological functions in the metabolism. All these properties have attracted the interest of scientific groups, in the field of coordination, inorganic and bioinorganic chemistries. In our continuation of synthesis and structural studies of carboxylate complexes, it was of great research interest to study the synthesis of new Cd(II) complex based on 2,3 pyridine dicarboxylic acid. Globally, the ring of the carboxylic anhydride can open by the hydrolysis reaction of 2,3-pyridine dicarboxylic anhydride to give directly a dicarboxylic acid or to prepare different carboxylate complexes [13] presenting strong and weak intermolecular interactions which could give; stability and $\mathrm{H}$-bonded supramolecular networks in the crystal packing. 


\section{Experimental}

\section{Chemical preparation}

All chemical and solvents used in this work were purchased by Sigma-Aldrich and used as received with the purity available.

A solution of $\mathrm{CdCl}_{2}(0.17 \mathrm{~g}, 1 \mathrm{mmol})$ dissolved in water $(6 \mathrm{~mL})$ was mixed with a solution of 2,3-pyridine dicarboxylic anhydride (PDCA) $(0.3 \mathrm{~g}, 2 \mathrm{mmol})$ dissolved in water. After stirring for two hours, the reaction mixture was evaporated slowly at room temperature. After two weeks, the resulting solution was filtered to obtain transparent crystals which were isolated and subjected to single-crystal X-ray diffraction (yield 79\%). Anal. Calc. for $\left\{\mathrm{C}_{14} \mathrm{H}_{12} \mathrm{CdN}_{2} \mathrm{O}_{10}\right\}$ : C, 34.95\%; H, $2.49 \% ; \mathrm{N}, 5.82 \%$. Found: C, $35.07 \% ; \mathrm{H}, 2.33 \%$; , $5.99 \%$.

\section{$\mathrm{X}$-ray single crystal structural analysis}

The single-crystal X-ray diffraction experiment was carried out using a Bruker Apex CCD diffractometer equipped with Mo radiation source $(\lambda=0.71073 \AA)$. Intensity data were collected at $193 \mathrm{~K}$ by means of the SMART software [14]. Reflection indexing, unit-cell parameters refinement, Lorentz-polarization correction, peak integration and background determination were performed using the SAINT software [15]. The crystal structure was solved by direct methods and refined with the SHELXS 2013 [16]. The crystal data are gathered in Table 1. The drawings were made with Vesta [17] and Mercury [18]. Basic parameters describing the measurement procedure as well as the refinement results are shown in Table 1. 
Table 1

Crystallographic data and structure refinement for $\left[\left(\mathrm{Cd}(2,3-\mathrm{pydcH})_{3}\right)\left(\mathrm{Cd}\left(\mathrm{H}_{2} \mathrm{O}\right)_{6}\right)\right]$.

\begin{tabular}{|ll|}
\hline Chemical formula & $\mathrm{C}_{14} \mathrm{H}_{12} \mathrm{CdN}_{2} \mathrm{O}_{10}$ \\
\hline$M_{\mathrm{r}}$ & 480.66 \\
\hline Crystal system & Trigonal \\
\hline Space group & $P \overline{3}$ \\
\hline Temperature $[\mathrm{K}]$ & 193 \\
\hline$a, c[\AA]$ & $14.729(2), 6.3260(13)$ \\
\hline$V\left[\AA^{3}\right]$ & $1188.4(4)$ \\
\hline$Z$ & 3 \\
\hline Radiation type & $M o K a$ \\
\hline$\mu\left[\right.$ mm $\left.{ }^{-1}\right]$ & 1.44 \\
\hline Crystal size $[\mathrm{mm}]$ & $0.25 \times 0.15 \times 0.15$ \\
\hline No. of observed reflections & 1920 \\
\hline$R_{\text {int }}$ & 0.018 \\
\hline$(\text { sin } \theta / \lambda)_{\text {max }}\left[\AA^{-1}\right]$ & 0.675 \\
\hline Final $R$ indices & $R 1=0.020, w R=0.051$ \\
\hline Goodness of fit $S$ & 1.16 \\
\hline$\Delta \rho_{\text {max }} \Delta \rho_{\text {min }}\left[\mathrm{e} \AA^{-3}\right]$ & $0.42,-0.41$ \\
\hline Cilations & \\
\hline
\end{tabular}

\section{Multipolar calculations}

The charge density of the molecules was modelled using the Hansen \& Coppens multipolar atom [19]. The charge density parameters were transferred from the ELMAM2 database of multipolar atoms [20]. The X-H bond lengths were elongated according to standard neutron diffraction distances [21]. The electrostatic energy between pairs of atoms in close contact was computed with the VMoPro module of the MoPro software [22]. The energy was obtained by direct summation over contacts between the reference and the surrounding molecules. To take into account only the shortest contacts which contribute to the Hirshfeld surface contacts atom/atom decomposition, a cut off of the sum of van der Waals radii plus $0.2 \AA$ was applied to the interatomic distance. Average $E_{\text {elec }}$ values were obtained by dividing the summation by the number of contacts. Hirshfeld surface and contact enrichment ratios were 
obtained with MoProViewer [23]. As X...Y and Y...X contact types yield similar contact surfaces and $E_{\text {elec }}$ values in the context of this study, the reciprocal contacts were merged together.

\section{Results And Discussion Structure description}

First of all, it is worth to note that the hydrolysis, which usually means the cleavage of chemical bonds by addition of water molecule, can open the ring of the 2,3-pyridine dicarboxylic anhydride because the water, acting as oxy-nucleophile, hydrolyzes anhydrides into their corresponding carboxylic acids. If the anhydride is part of a ring, the ring will open, producing one molecule with two carboxylic acid groups (its corresponding acid), as depicted in Scheme 1.

Crystallographic data and detailed refinement results of the coordinated compound are presented in Table 1. The bond lengths and angles are given in Table 2 while hydrogen bonds present in the structure are shown in Table 3. The reaction of 2,3-pyridine dicarboxylic anhydride with cadmium dichloride in water leads to a chelate complex with the formula $\left[\left(\mathrm{Cd}(2,3-\mathrm{pdcH})_{3}\right)\left(\mathrm{Cd}\left(\mathrm{H}_{2} \mathrm{O}\right)_{6}\right)\right](\mathrm{Fig} .1)$. In this complex structure, the asymmetric unit of the title compound contains two crystallographically independent $\mathrm{Cd}(\mathrm{II})$ ions. The $\mathrm{Cd}(1)$ center is octahedrally coordinated to six water molecules $\left(01,01^{\mathrm{i}}(i=-x,-y,-\mathrm{z}), 01^{\mathrm{ii}}(\mathrm{ii}=x-\right.$ $y, x,-\mathrm{z}), 01^{\mathrm{iii}}(\mathrm{iii}=-x+y,-x, \mathrm{z}), 01^{\mathrm{iv}}(\mathrm{iv}=-y, x-y, \mathrm{z})$ and $01^{\mathrm{v}}(\mathrm{v}=y,-x+y,-\mathrm{z})$. There is also a six coordination environment around the $\mathrm{Cd}(2)$ ion with three chelating ligands derived from the 2,3-pyridine dicarboxylato mono anion. It is coordinated to the oxygen and nitrogen atoms $(02, N 1),\left(O 2^{v i}, N 1^{v i}(v i=-x+y+1,-x+1, z)\right.$ and $\mathrm{O}^{\mathrm{vii}}{ }^{\mathrm{vi}} \mathrm{N}^{\mathrm{vii}}$ (vii= $\left.-\mathrm{y}+1, \mathrm{x}-\mathrm{y}, \mathrm{z}\right)$ of the three 2,3-pdcH ligands. The geometrical features of the $\mathrm{CdO}_{3} \mathrm{~N}_{3}$ octahedron are reported in Table 2. The three angles around the $\mathrm{Cd}$ atom (01-Cd1-01', 01 ${ }^{\mathrm{ii}}-\mathrm{Cd} 1-01^{\mathrm{iii}}$ and $01^{\mathrm{iv}}-\mathrm{Cd} 1-01^{\mathrm{V}}$ are all flat with angles value equal to $180^{\circ}$, giving octahedral geometry (Fig. 2). The bond distances (Table 2) vary between 2.2552(15) and 2.3280 (15) $\AA$ and compare well to those reported for similar octahedral $\mathrm{Cd}(\mathrm{II})$ complexes [24]. The bond angles around the $\mathrm{Cd}(2)$ atom vary between $72.52(5)$ and $159.44(5)^{\circ}$ indicating that the $\mathrm{CdN}_{3} \mathrm{O}_{3}$ species has a slightly distorted octahedral geometry. It is worth to note that in the lattice structure, the $\left[\mathrm{Cd}\left(\mathrm{H}_{2} \mathrm{O}\right)_{6}\right]$ entities are situated on the vertices of the unit cell (Fig. 2). The structure of the organic cation contains an unusual $\mathrm{COOH}$ carboxylic acid with the proton lying in the anti position. This is due to a stabilization of the anti conformation by an intramolecular hydrogen bond. The great abundance of hydrogen bonding donors and acceptors leads to a complex three-dimensional hydrogen bonding network. The carboxylate group shows strong intramolecular hydrogen bonding $(0-W O \cdots 0)$ between the water molecules and the oxygen atoms of the neutral carboxylic acid and the carbonyl oxygen of another coordinating carboxylate group (Fig. 3). These entities are connected via O-WO... O hydrogen bonds to form layers parallel to the (a,b) plane (Fig. 3 ). 
Table 2

Selected bond lengths $(\AA)$ and bond angles $\left(^{\circ}\right)$ for non-H atoms with esd values in parenthesis for the title compound

\begin{tabular}{|c|c|c|c|}
\hline $\mathrm{Cd} 1-01^{i}$ & $2.2494(16)$ & $\mathrm{N} 1-\mathrm{C} 1$ & $1.334(2)$ \\
\hline $\mathrm{Cd} 1-01^{\mathrm{ii}}$ & $2.2494(16)$ & $\mathrm{N} 1-\mathrm{C} 5$ & $1.343(2)$ \\
\hline $\mathrm{Cd} 1-01^{\mathrm{iii}}$ & $2.2494(16)$ & $\mathrm{C} 1-\mathrm{C} 2$ & $1.378(3)$ \\
\hline $\mathrm{Cd} 1-01^{\text {iv }}$ & $2.2494(16)$ & $\mathrm{C} 2-\mathrm{C} 3$ & $1.374(3)$ \\
\hline $\mathrm{Cd} 1-01^{\mathrm{v}}$ & $2.2494(16)$ & C3-C4 & $1.390(2)$ \\
\hline Cd1-01 & $2.2495(16)$ & C4-C5 & $1.385(2)$ \\
\hline $\mathrm{Cd} 2-02^{\mathrm{vi}}$ & $2.2551(13)$ & $\mathrm{C} 4-\mathrm{C} 7$ & $1.502(2)$ \\
\hline $\mathrm{Cd} 2-02^{\mathrm{vii}}$ & $2.2552(13)$ & C5-C6 & $1.518(2)$ \\
\hline $\mathrm{Cd} 2-02$ & $2.2552(13)$ & C6-03 & $1.247(2)$ \\
\hline $\mathrm{Cd} 2-\mathrm{N} 1$ & $2.3280(15)$ & C6-02 & $1.248(2)$ \\
\hline $\mathrm{Cd} 2-\mathrm{N} 1^{\mathrm{vi}}$ & $2.3280(15)$ & C7-05 & $1.201(2)$ \\
\hline $\mathrm{Cd} 2-\mathrm{N} 1^{\mathrm{vii}}$ & $2.3280(15)$ & C7-O4 & $1.297(2)$ \\
\hline O1-H01 & $0.810(17)$ & O1-HO2 & $0.792(17)$ \\
\hline $01^{i}-\mathrm{Cd} 1-01^{i i}$ & $95.02(7)$ & $02^{\mathrm{vi}}-\mathrm{Cd} 2-02^{\mathrm{vii}}$ & $93.06(5)$ \\
\hline 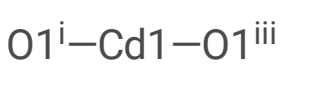 & $84.98(7)$ & $\mathrm{O} 2^{\mathrm{vi}}-\mathrm{Cd} 2-02$ & $93.06(5)$ \\
\hline 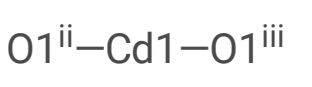 & 180. & $\mathrm{O} 2^{\mathrm{vii}-\mathrm{Cd} 2-02}$ & $93.06(5)$ \\
\hline $01^{\mathrm{i}}-\mathrm{Cd} 1-01^{\mathrm{iv}}$ & $84.98(7)$ & $\mathrm{O} 2^{\mathrm{vi}}-\mathrm{Cd} 2-\mathrm{N} 1$ & $159.44(5)$ \\
\hline $01^{\mathrm{ii}}-\mathrm{Cd} 1-01^{\mathrm{iv}}$ & $84.98(7)$ & 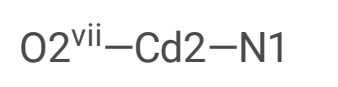 & $102.08(5)$ \\
\hline 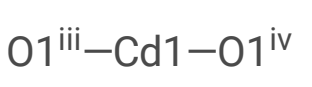 & $95.02(7)$ & $\mathrm{O} 2-\mathrm{Cd} 2-\mathrm{N} 1$ & $72.52(5)$ \\
\hline 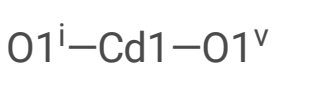 & $95.02(7)$ & $\mathrm{O} 2^{\mathrm{vi}}-\mathrm{Cd} 2-\mathrm{N} 1^{\mathrm{vi}}$ & $72.52(5)$ \\
\hline $01^{\mathrm{ii}-C d 1-01^{\mathrm{v}}}$ & $95.02(7)$ & $\mathrm{O} 2^{\mathrm{vii}}-\mathrm{Cd} 2-\mathrm{N} 1^{\mathrm{vi}}$ & $159.44(5)$ \\
\hline 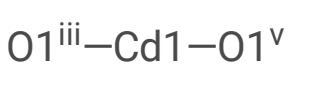 & $84.98(7)$ & $\mathrm{O} 2-\mathrm{Cd} 2-\mathrm{N} 1^{\mathrm{vi}}$ & $102.08(5)$ \\
\hline $01^{\mathrm{iv}}-\mathrm{Cd} 1-01^{\mathrm{v}}$ & 180. & $\mathrm{~N} 1-\mathrm{Cd} 2-\mathrm{N} 1^{\mathrm{vi}}$ & $95.75(5)$ \\
\hline
\end{tabular}




\begin{tabular}{|c|c|c|c|}
\hline $\mathrm{Cd} 1-01^{i}$ & 2.2494 (16) & $\mathrm{N} 1-\mathrm{C} 1$ & $1.334(2)$ \\
\hline $01^{i}-\mathrm{Cd} 1-01$ & 180. & $\mathrm{O} 2^{\mathrm{vi}}-\mathrm{Cd} 2-\mathrm{N} 1^{\mathrm{vii}}$ & $102.08(5)$ \\
\hline $01^{\mathrm{ii}}-\mathrm{Cd} 1-01$ & $84.98(7)$ & $\mathrm{O} 2^{\mathrm{vii}}-\mathrm{Cd} 2-\mathrm{N} 1^{\mathrm{vii}}$ & $72.52(5)$ \\
\hline $01^{\mathrm{iii}-\mathrm{Cd} 1-01}$ & $95.02(7)$ & $\mathrm{O} 2-\mathrm{Cd} 2-\mathrm{N} 1^{\mathrm{vii}}$ & $159.44(5)$ \\
\hline $01^{\mathrm{iv}}-\mathrm{Cd} 1-01$ & $95.02(7)$ & $\mathrm{N} 1-\mathrm{Cd} 2-\mathrm{N} 1^{\mathrm{vii}}$ & $95.75(5)$ \\
\hline $01^{v}-\mathrm{Cd} 1-01$ & $84.98(7)$ & $\mathrm{N} 1^{\mathrm{vi}}-\mathrm{Cd} 2-\mathrm{N} 1^{\mathrm{vii}}$ & $95.75(5)$ \\
\hline
\end{tabular}

Table 3

Geometric details of hydrogen bonds $\left(\AA,^{\circ}\right)$ (D-donor; A-acceptor; H-hydrogen).

\begin{tabular}{|c|c|c|c|c|}
\hline$D-\mathrm{H} \cdots A$ & $D-\mathrm{H}$ & $H \cdots A$ & $D \cdots A$ & $D-\mathrm{H} \cdots A$ \\
\hline $01-W 01 \cdots 05^{i}$ & $0.810(17)$ & $2.06(2)$ & $2.809(2)$ & 154(3) \\
\hline $01-W 02 \cdots 05^{i i}$ & $0.792(17)$ & $2.56(3)$ & $3.012(2)$ & 118(3) \\
\hline $01-W 02 \cdots 03^{i i i}$ & $0.792(17)$ & $2.38(2)$ & $2.980(2)$ & 133(3) \\
\hline $01-W 02 \cdots 05^{i i}$ & $0.792(17)$ & $2.56(3)$ & $3.012(2)$ & 118(3) \\
\hline $\mathrm{O} 4-\mathrm{OH} 4 \cdots \mathrm{O} 2^{\mathrm{iv}}$ & $0.820(16)$ & 2.66(2) & $3.0538(18)$ & 112(2) \\
\hline $\mathrm{O} 4-\mathrm{OH} 4 \cdots 3^{\mathrm{iv}}$ & $0.820(16)$ & 1.784(18) & $2.5763(18)$ & 162(2) \\
\hline
\end{tabular}

\section{Hirshfeld surface and enrichment ratio}

The Hirshfeld surface is representative of the region in space where molecules come into contact with each other allowing the analysis of the chemical nature of intermolecular interactions in the crystal. The contact enrichment ratio is obtained by comparing the actual contacts $C_{\mathrm{XY}}$ in the crystal with those computed as if all types of contacts had the same probability to form. An enrichment ratio larger than unity for a given pair of chemical species $X$...Y indicates that these contacts are over-represented in the crystal [25]. The analysis of contact types and their enrichment were computed with the program MoProViewer [26]. 
The Hirshfeld surface was computed around all entities present in the crystal (the $\mathrm{Cd}^{++}$cations, the water molecules and the organic anions) in order to analyze the crystal contacts (Fig. 4). The multiplicity of the cadmium atoms was taken into account in the calculation of the surface areas.

The Cd...N coordination bond represents, by far, the most enriched contact with $E_{\mathrm{CdN}}=7.7$, followed by the Cd...O coordination bond, which is the most abundant contact type (Table 4).

Table 4. Nature of intermolecular contacts on the Hirshfeld surface by chemical types. The second row contains the contribution $S_{\mathrm{x}}$ of each chemical type $\mathrm{X}$ on the Hirshfeld surface. The third part of the Table show the \% Cxy of the contact types on the surface. The lower part of the Table shows the Exy contact enrichment ratios. The major Cxy contact types and the Exy ratios much larger than unity (enriched contacts) are highlighted in bold characters. The hydrophobic $\mathrm{Hc}$ atoms bound to carbon were distinguished from the more polar Ho hydrogen atom from water. Chemical types have been regrouped in hydrophobic $(\mathrm{C}, \mathrm{Hc})$ and charged $(\mathrm{Cd}, \mathrm{N}, \mathrm{O}, \mathrm{Ho})$ atoms.

\begin{tabular}{|lllllll|}
\hline Atom & $\mathrm{Cd}$ & $\mathrm{N}$ & $\mathrm{O}$ & $\mathrm{Ho}$ & $\mathrm{Hc}$ & $\mathrm{C}$ \\
\hline Surface \% & 18.6 & 3.7 & 27.5 & 14.0 & 14.4 & 20.7 \\
\hline Cd & 0.3 & & & & & \\
$\mathrm{~N}$ & 10.5 & 0.0 & & & & \\
\hline O & 26.2 & 0.0 & 1.4 & & & \\
\hline Ho & 6.4 & 0.0 & 14.3 & 0.3 & & \\
Hc & 4.3 & 0.6 & 7.0 & 1.0 & 2.0 & \\
C & 5.9 & 0.3 & 5.5 & 3.0 & 4.9 & 6.2 \\
\hline Cd & 0.09 & & & & & \\
\hline N & 7.7 & 0.00 & & & & \\
O & 2.6 & 0.00 & 0.18 & & & \\
\hline Ho & 1.23 & 0.00 & 1.86 & 0.16 & & \\
\hline Hc & 0.81 & 0.54 & 0.68 & 0.24 & 0.96 & \\
\hline C & 0.77 & 0.20 & 0.48 & 0.51 & 0.82 & 1.45 \\
\hline
\end{tabular}

The $\mathrm{Cd} 1$ cation is coordinated by six symmetry-related water oxygen atoms while the $\mathrm{Cd} 2$ cation is coordinated by three symmetry-related oxygen carboxylate and nitrogen atoms. The second most abundant contact is constituted by the $0 . . . \mathrm{H}-\mathrm{O}$ strong hydrogen bonds between the water molecule, the carboxylic acid $\mathrm{COOH}$ and the carboxylate group, which is over-represented at $E_{\mathrm{OHO}}=1.86$. 
The $\mathrm{C}_{5} \mathrm{~N}$ aromatic cycle of the organic cation forms antiparallel stacking with itself, resulting in quite enriched C...C interactions (Fig. 5). About $45 \%$ of the Hirshfeld surface is of hydrophobic in nature, constituted by atoms $\mathrm{C}$ and $\mathrm{Hc}$ but the hydrophobic contacts between these atoms represent only $13 \%$ of the surface. When the hydrophilic/charged atoms are considered, the contact surface between these atoms represents $60 \%$, which is significantly over-represented at $E=1.46$. Hydrophobic contacts (between $\mathrm{Hc}$ and $\mathrm{C}$ ) are over-represented to a lesser extend at $E=1.06$. The cross interactions between charged and hydrophobic atoms $(E=0.58)$ are strongly under-represented, which is also the case for the weak attractive hydrogen bonds $\mathrm{C}-\mathrm{H} . . . \mathrm{O}$ and $\mathrm{C}-\mathrm{H} . . . \mathrm{N}$.

The electrostatic energy between pairs of atoms in contact was computed with the MoProSuite software [27] using the Hansen \& Coppens (1978) multipolar atom model. The X-H bonds were elongated according standard neutron distances [28]. The electron density of the compound was transferred from the ELMAM2 multipolar atoms database [29]. The attribution of a +1.794 e charge to the cadmium atoms (which are not in the database) permitted to set the asymmetric electrically neutral.

The contribution of the different contact types to the electrostatic energy is shown in Fig. 6 . The strongest attractive contributions come from ionic bridges $\mathrm{O} . . . \mathrm{Cd}$ and strong $\mathrm{O}-\mathrm{H} . . . \mathrm{O}$ hydrogen-bonds followed by N....Cd ionic bridge. There are some repulsive electrostatic $\mathrm{O} . . . \mathrm{O}, \mathrm{Ho} . . . \mathrm{Ho}$ and Ho...Cd counterparts which are derived from the $\mathrm{O} . . . \mathrm{H}-\mathrm{O}$ hydrogen bonds and $\mathrm{O} . . \mathrm{Cd}$ ionic bridge. Globally the $\mathrm{O}$...Cd interactions account for nearly all of the summed energy of all contacts. There are 29 different $\mathrm{C}$.... 0 contacts with energy values in the range $[-8,+18] \mathrm{kJ} / \mathrm{mol}$. The repulsive $0 . . . \mathrm{C}$ interactions are due to stacking of the carboxylate group on the aromatic ring and are compensated by attractive $0 . . . \mathrm{Hc}$ interactions with the aromatic hydrogen atoms.

Figure 7 shows that the three strongest electrostatic interactions (N...Cd, O...Cd, O...Ho) are also the most enriched ones and constitute the driving force in the crystal packing formation. For the weaker or repulsive interactions, there is no clear correlation between the two descriptors. The C...C stacking contacts appear peculiar with significant enrichment 1.45 but insignificant $<E_{\text {elec }}>$ value.

\section{Frontier Molecular Orbitals (HOMO-LUMO) Analysis}

The energy of frontier orbitals HOMO stands for "Highest Occupied Molecular Orbital" and LUMO stands for "Lowest Unoccupied Molecular Orbital", plays a significant contribution in describing the nature of chemical reactivity, chemical behaviour and structural properties of the coordination compounds. HOMOLUMO orbitals were calculated only on the cadmium species surrounded by the three organic ligands. The calculations were made with the Gaussian A09 software by using the B3LYP hybrid density functional and the $6-31+G *$ base set for all atoms except for cadmium for which the LanL2DZ pseudopotential was used.

The highest occupied molecular orbital ( $\mathrm{HOMO})$ is mainly located on the carboxylic $\left(\mathrm{COO}^{-}\right)$groups of the $\left[\mathrm{Cd}(2,3-\mathrm{pdcH})_{3}\right]^{2-},(2,3-\mathrm{pdcH}=2,3-p y r i d i n e d i c a r b o x y l i c ~ a c i d)$ anion, while the lowest unoccupied molecular orbital (LUMO) is mainly located on the aromatic rings. 
The ionization energy (associated to the ability of electron transfer) is deduced from the HOMO energy value while. The electron affinity (which describes the ability of electron accepting) is defined by the value of the LUMO energy [30].

Moreover, the chemical reactivity descriptions such as electronegativity, Chemical Hardness, Softness and electrophilicity index can be deduced from the HOMO and LUMO energies and are given as follows using Koopman's theorem:

$$
\begin{aligned}
& \mu \approx-\chi=-\frac{I+A}{2} \text { (Electronegativity) } \\
& \eta \approx \frac{I-A}{2} \text { (Chemical hardness) } \\
& \zeta=\frac{1}{2 \eta} \text { (Softness) } \\
& \psi=\frac{\mu^{2}}{2 \eta} \text { (Electrophilicity index) }
\end{aligned}
$$

where ionized energy $\mathrm{I} \approx-\mathrm{E}(\mathrm{HOMO})=3.65 \mathrm{eV}$, electron affinity $\mathrm{A}(\mathrm{eV}) \approx-\mathrm{E}(\mathrm{LUMO})=-0.30 \mathrm{eV}$ [31-33]. The energy gap between the HOMO and LUMO energies has been calculated as $3.95 \mathrm{eV}$ (Fig. 8). This large energy gap characterizes a high chemical hardness and kinetic stability of the new coordination compound. The electro-negativity, chemical hardness, softness, and electrophilicity index of the coordination compound were calculated to be $-1.70 \mathrm{eV}, 1.97 \mathrm{eV}, 0.253 \mathrm{eV}$ and $0.731 \mathrm{eV}$.

The density of state (DOS) spectrum of the title compound was plotted with the GaussSum software using information from the Gaussian output file and is shown in Fig. 9. It shows the number of available molecular orbitals including compositions and their contributions to the chemical bonding at different levels of energies. The red and green lines of the plot indicate the virtual and occupied orbitals, respectively, and also provide an understanding of the molecular orbitals character in a particular area. The DOS plot and its energy levels also corroborate the Frontier Molecular Orbitals analysis.

\section{Molecular Electrostatic Potential (MEP)}

The molecular electrostatic potential surface (MEP) allows to study the molecular reactive behaviour towards electrophilic and nucleophilic attacks and to determine the electrophile (electron-deficient positively charged species) and nucleophile (electron rich negatively charged species) sites. The negative regions of the MEP which represent high electron density appear in red and are referred to the electrophilic reactivity while the positive (blue) regions are referred to the nucleophilic reactivity. As it can be seen from Fig. 10, the red region located around the $\mathrm{Cd}$ atom can be considered as the electrophilic reactivity center while the positive region is localized on the ligands which will be the reactive sites for nucleophilic attack (these sites are involved in the intermolecular contacts) [34-38].

\section{Conclusion}


The $\left[\left(\mathrm{Cd}(2,3-\mathrm{pyzdcH})_{3}\right)\left(\mathrm{Cd}\left(\mathrm{H}_{2} \mathrm{O}\right)_{6}\right)\right]$ material was obtained by reacting cadmium dichloride and 2,3pyridinedicarboxylic acid. This new compound crystallizes in the trigonal space group $P \overline{3}$. The 2,3pyridinedicarboxylic ligand coordinates in a bidentate chelate mode via the pyridine nitrogen atom and oxygen atom of the mono deprotonated 2-carboxylic group. The MEP map shows that the negative potential sites are on the $\mathrm{Cd}$ (II) cation while the positive potential sites are around the 2,3pyridinedicarboxylic ligands. The HOMO-LUMO energy gap suggests a good stability of the title compound.

\section{Declarations}

\section{Supplementary data}

Crystallographic data for the structural analysis have been deposited at the Cambridge Crystallographic Data Centre, CCDC No 1941189 These data can be obtained free of charge via http://www.ccdc.cam.ac.uk/conts/retrieving.html, or from the CCDC, 12 Union Road, Cambridge, CB2 1EZ, UK: fax: (+44) 01223-336-033; e-mail: deposit@ccdc.cam.ac.

\section{References}

1. F.A. Cotton, G. Wilkinson, C.A. Murillo, M. Bochmann, Advanced Inorganic Chemistry, 6. (th ed., John Wiley \& Sons: New York, 1999), pp. 814-835

2. H. Adams, M.S. Shongwe, I. Al-Bahri, E. Al-Busaidi, M.J. Morris, Acta Cryst C61, m497-m500 (2005)

3. P.S. Subramanian, D. Srinivas, Polyhedron 15, 985-989 (1996)

4. S. Yan, X. Li, X. Zheng, J. Mol. Struct. 929, 105-111 (2009)

5. L. Yang, D.C. Crans, S.M. Miller, A. Iacour, O.P. Anderson, P.M. Kaszynski, M.E. Godzala III, L.D. Austin, G. R. Willysky. Inorg. Chem 41, 4859-4871 (2002)

6. M.A. Sharif, H. Aghabozorg, A. shokrollahi, M. Shamsipur, A Moghimi and GK Ckelbick polish. J.Chem -80, 847-863 (2006)

7. M. Chatterjee, M. Maji, S. Ghosh, T.C.W.- Mak, K Studies of V (111) complexes, Chem. Soc. Dalton Trans. 21, 3641-3645 (1998)

8. Z. Aghajani, M.A. Sharif, H. Aghabozorg, A. Naderpour, Acta Cryst E62, m830-m832 (2006)

9. X. Liang, M. Weishaupl, J.A. Parkinson, S. Parsons, P.A. McGregor, P J Sadler. Chem. Eur. J 9, 4709 (2003)

10. S. Ates, E. Gok, O. Karadag, O. Oktar, M. Kiremtci, Hacettepe Bulletin of Natural Science and Engineering 23, 109-127 (1993)

11. L.C. Nathan, T.D. Mai, J. Chem. Cryst 30, 509-518 (2000)

12. T.A. Slieman, W.L. Nicholson, Appl. Environ. Microbiol. 67(3), 1274-1279 (2001) 
13. Y.A. Ammar, Y.A. Mohamed, A.M.Sh. El-Sharief, M.S.A. El-Gaby, S.Y. Abbas, Reactivity of 2. J. Chem. Sci. CSJ 16, 1-11 (2011)

14. SMART V5.054, Bruker Analytical X-ray Systems, Madison,WI (2001)

15. SAINT + V6.45, Bruker Analytical X-ray Systems, Madison,WI (2001)

16. G.M. Sheldrick, Acta Cryst. C71, 3-8 (2015)

17. K. Momma, F. Izumi, J. Appl. Cryst. 44, 1272-1276 (2011)

18. C.F. Macrae, P.R. Edgington, P. McCabe, E. Pidcock, G.P. Shields, R. Taylor, M. Towler, J. van de Streek, J. Appl. Crystallogr. 39, 453-457 (2006)

19. N.K. Hansen, P. Coppens, Acta Cryst. A 34, 909-921 (1978)

20. S. Domagala, B. Fournier, D. Liebschner, B. Guillot, C. Jelsch (2012), Acta Cryst. A68, 337-351

21. F.H. Allen, Acta Cryst. B58, 380-388 (2002)

22. C. Jelsch, B. Guillot, A. Lagoutte, C. Lecomte, J. Appl. Cryst. 38, 38-54 (2005)

23. B. Guillot, E. Enrique, L. Huder, C. Jelsch, Acta Cryst. A70, C279 (2014)

24. A.M. Baruah, A. Karmakar, A.K. Jubaraj, B. Baruah, Hydrolytic ring opening reactions of anhydrides for first row transition metal dicarboxylate complexes. Polyhedron $26,4518-4524$ (2007)

25. C. C.Jelsch, L. Ejsmont, I.U.C.J. Huder (2014). 1, 119-128

26. B. Guillot, E. Enrique, L. Huder, C. Jelsch, MoProViewer: a tool to study proteins from a charge density science perspective. Acta Cryst. A70, C279 (2014)

27. C. Jelsch, S. Soudani, C. Ben Nasr, IUCr J 2, 327-340 (2015)

28. F.H. Allen, I.J. Bruno, Bond lengths in organic and metal-organic compounds revisited: $\mathrm{X}-\mathrm{H}$ bond lengths from neutron diffraction data. Acta Crystallogr. B66, 380-386 (2010)

29. S. Domagała, B. Fournier, D. Liebschner, B. Guillot, C. Jelsch, An improved experimental databank of transferable multipolar atom models-ELMAM2. Construction details and applications. Acta Crystallogr. A68, 337-351 (2012)

30. X.H. Li, X.R. Liu, X.Z. Zhang, Molecular structure and vibrational spectra of three substituted 4thioflavones by density functional theory and ab initio HartreeeFock calculations. Spectrochim. Acta. A 78, 528-536 (2011)

31. R.G. Parr, R.G. Pearson, Absolute hardness: companion parameter to absolute electronegativity. Soc. J. Am. Chem. 105(26), 7512-7516 (1983)

32. R.G. Pearson, Absolute and hardness correlated with molecular electronegativity orbital theory, Proc. Natl. Acad. Sci. USA 83 (22) (1986) 8440-8441

33. H. Saeidian, M. Sahandi, Comprehensive DFT study on molecular structures of of Lewisites in support the chemical weapons convention. J. Mol. Struct. 110 0, 86-495 4 (2015)

34. A. Tokatlı, E. Ozen, F. Ucun, S. Bahçeli, Quantum chemical computational studies on 5-(4bromophenylamino)-2-methylsulfanylmethyl-2H-1,2,3-triazol-4-carboxylic acid ethyl ester. Spectrochim. Acta A 78, 1201-1211 (2011) 
35. E. Scrocco, J. Tomasi, Electronic molecular structure, reactivity and intermolecular forces: an euristic interpretation by means of electrostatic molecular potentials. Adv. Quant. Chem. 11, 115-193 (1978)

36. F.J. Luque, J.M. Lopez, M. Orozco, Perspective on electrostatic interactions of a solute with a continuum. A direct utilization of ab initio molecular potentials for the prevision of solvent effects. Theor. Chem. Acc. 103, 343-345 (2000)

37. N. Okulik, A.H. Jubert, Theoretical analysis of the reactive sites of non-esteroidal anti-inflammatory drugs. Int. Electron J. Mol. Des. 4, 17-30 (2005)

38. H. Saeidian, M. Sahandi, Comprehensive DFT study on molecular structures of lewisites in support of the chemical weapons convention. J. Mol. Struct. 1100, 486-495 (2015)

\section{Figures}

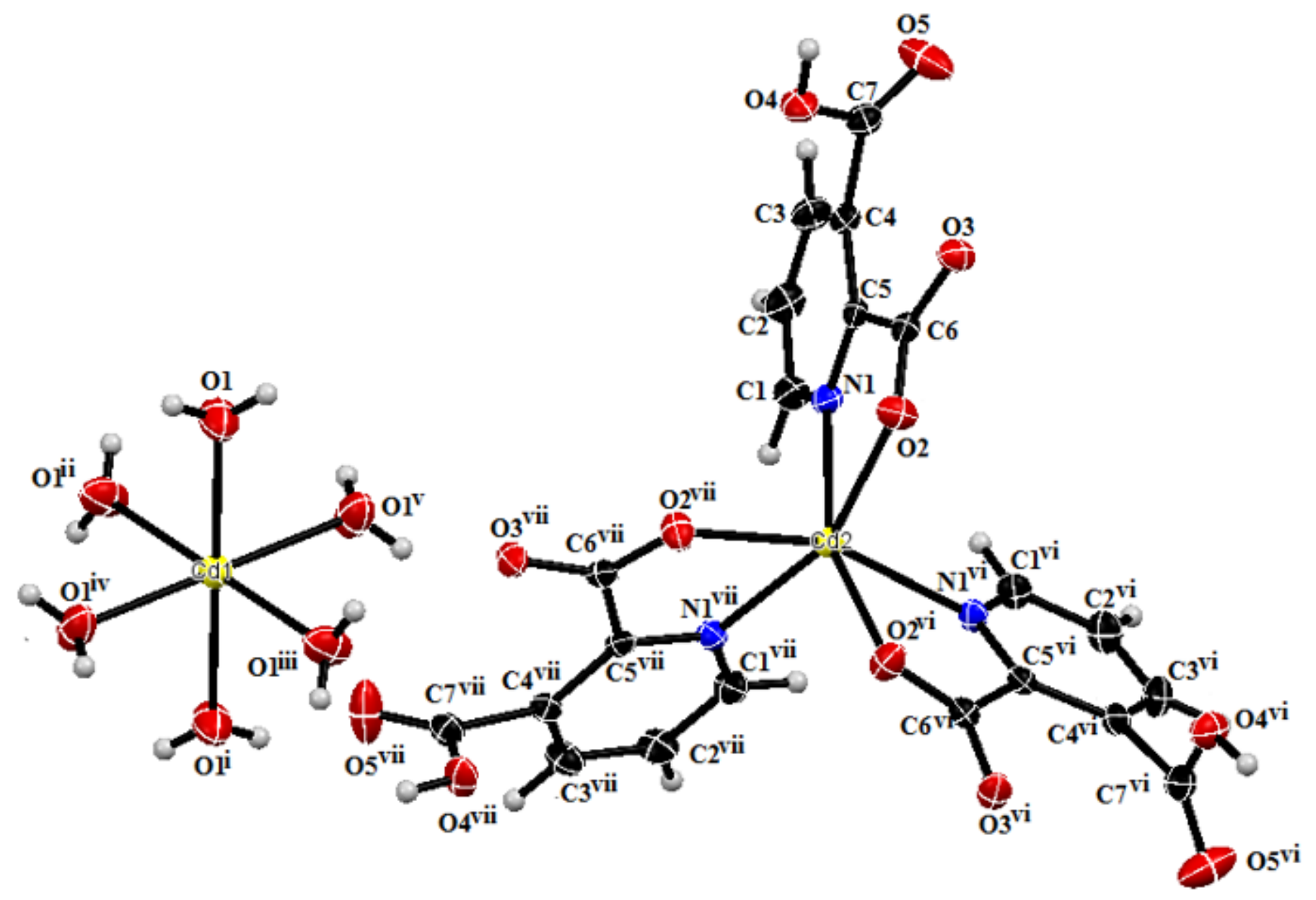

Figure 1

Structure of $[(\mathrm{Cd}(2,3-\mathrm{pyzdcH}) 3)(\mathrm{Cd}(\mathrm{H} 2 \mathrm{O}) 6)]$. 


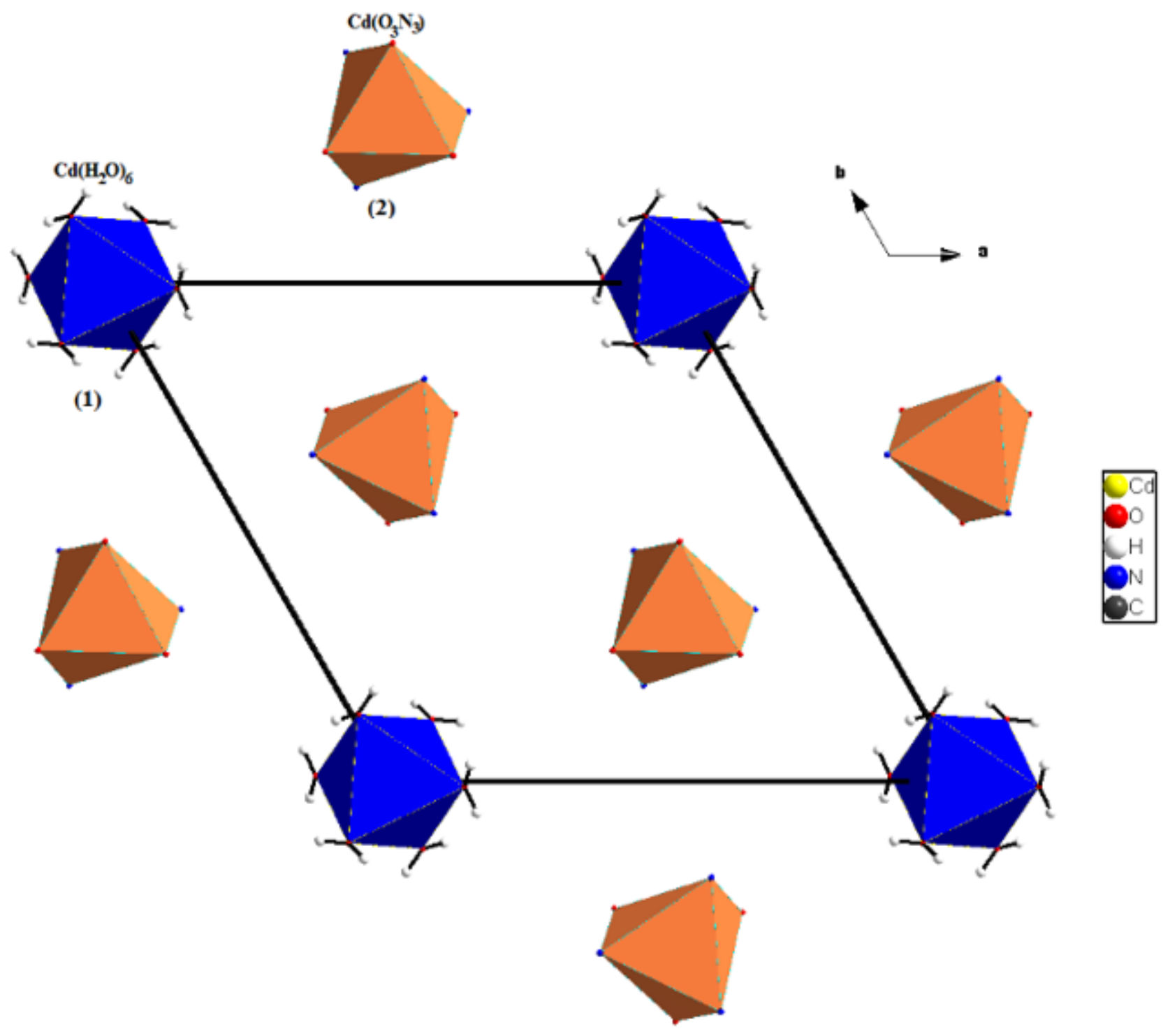

Figure 2

Coordination environment of the $\mathrm{Cd}(\mathrm{II})$ atom in the title compound 


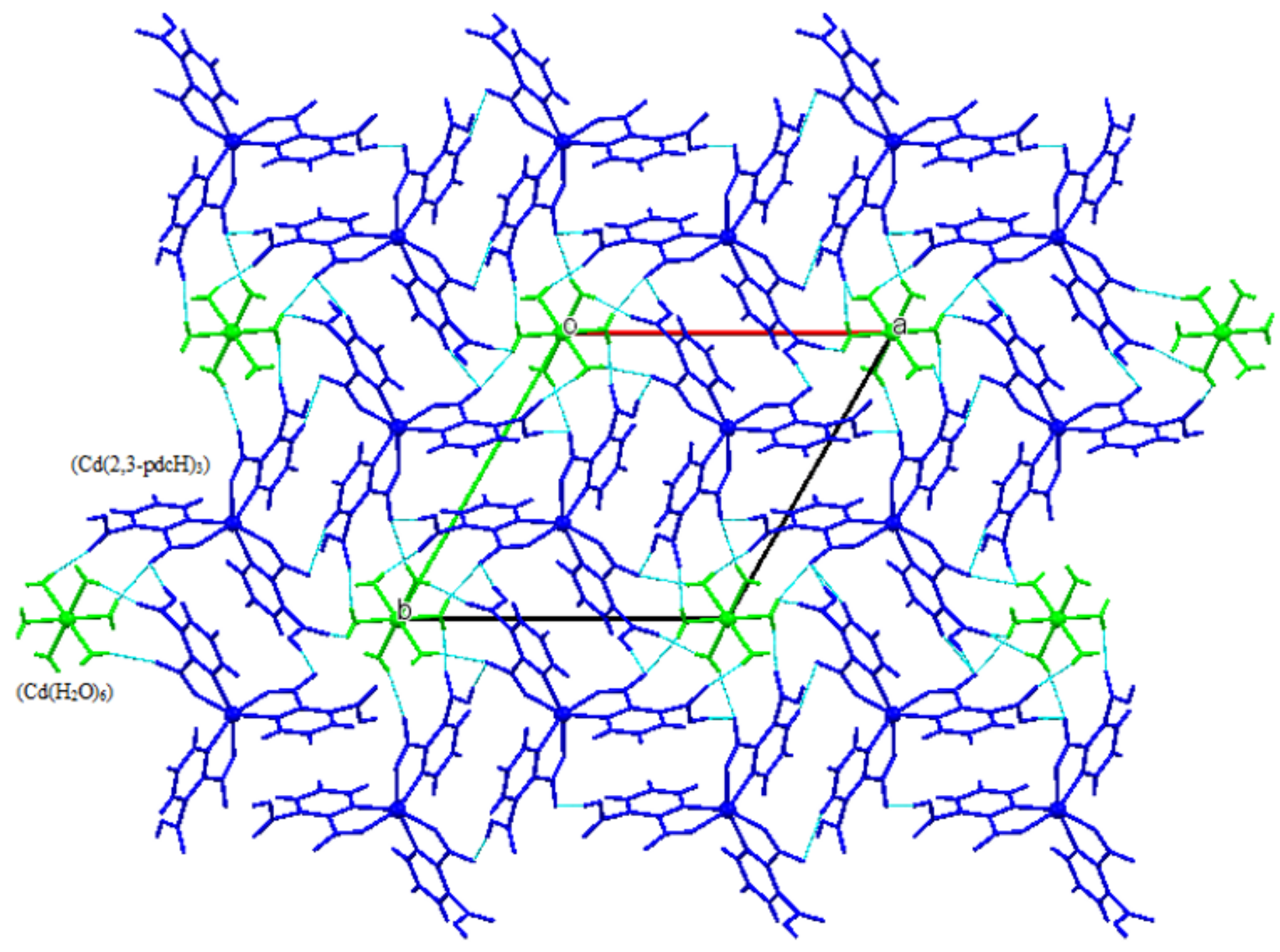

Figure 3

View of the three-dimensional supramolecular structure of the title compound along the $\mathrm{c}$ axis, incorporating hydrogen bonds (dashed lines). 

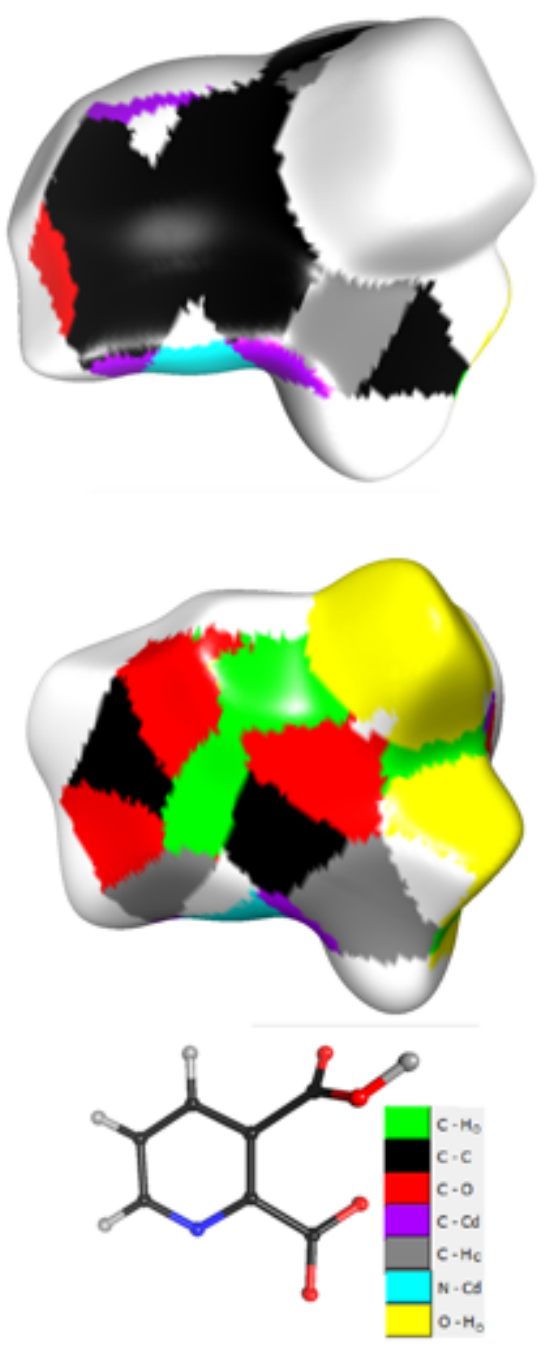

\section{Figure 4}

Hirshfeld surface around the organic anion, colored according to some of the contact types. (a) front view, (b) rear view, (c) orientation of the molecule and contact type color chart. 


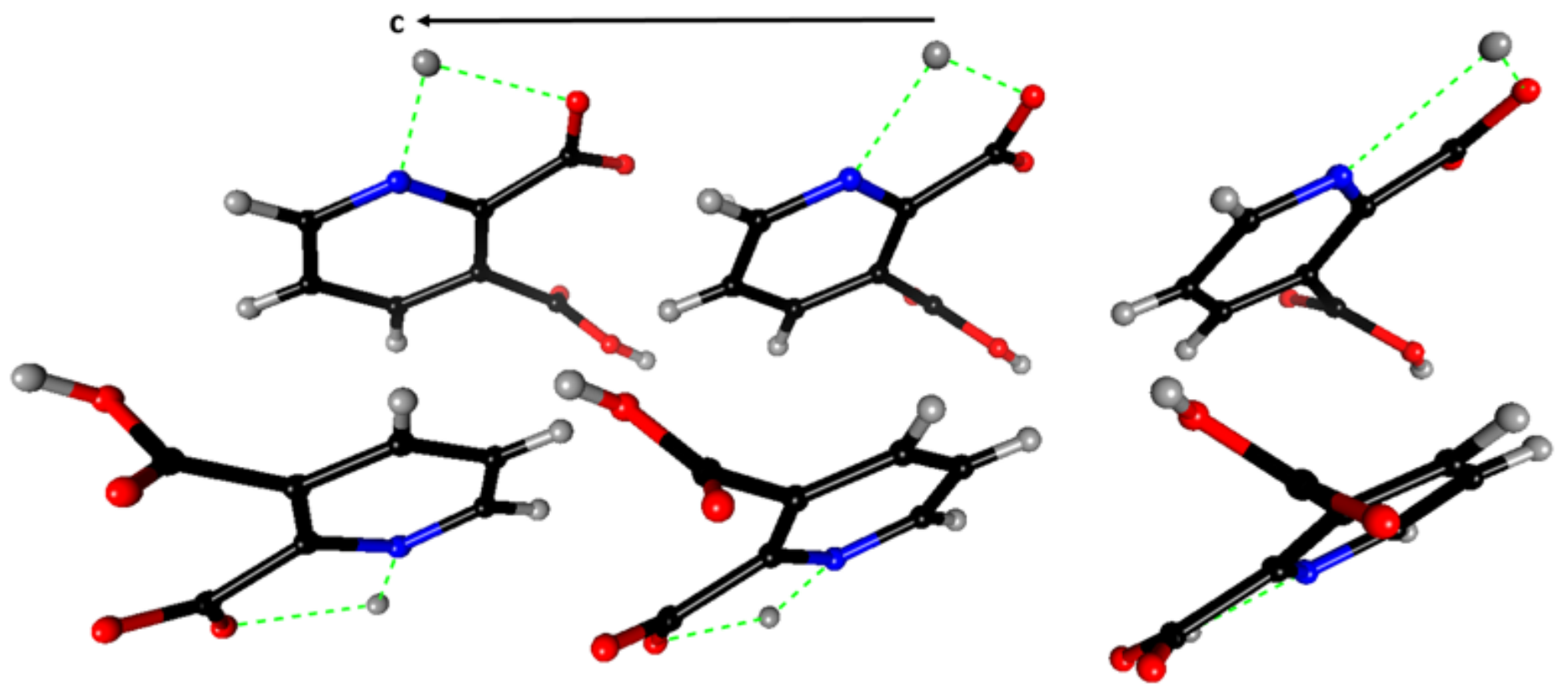

Figure 5

Crystallographic auto-stereogram showing the stacking of aromatic cycles as well as the stacking of the carboxylate group on the other side of the cycles. 


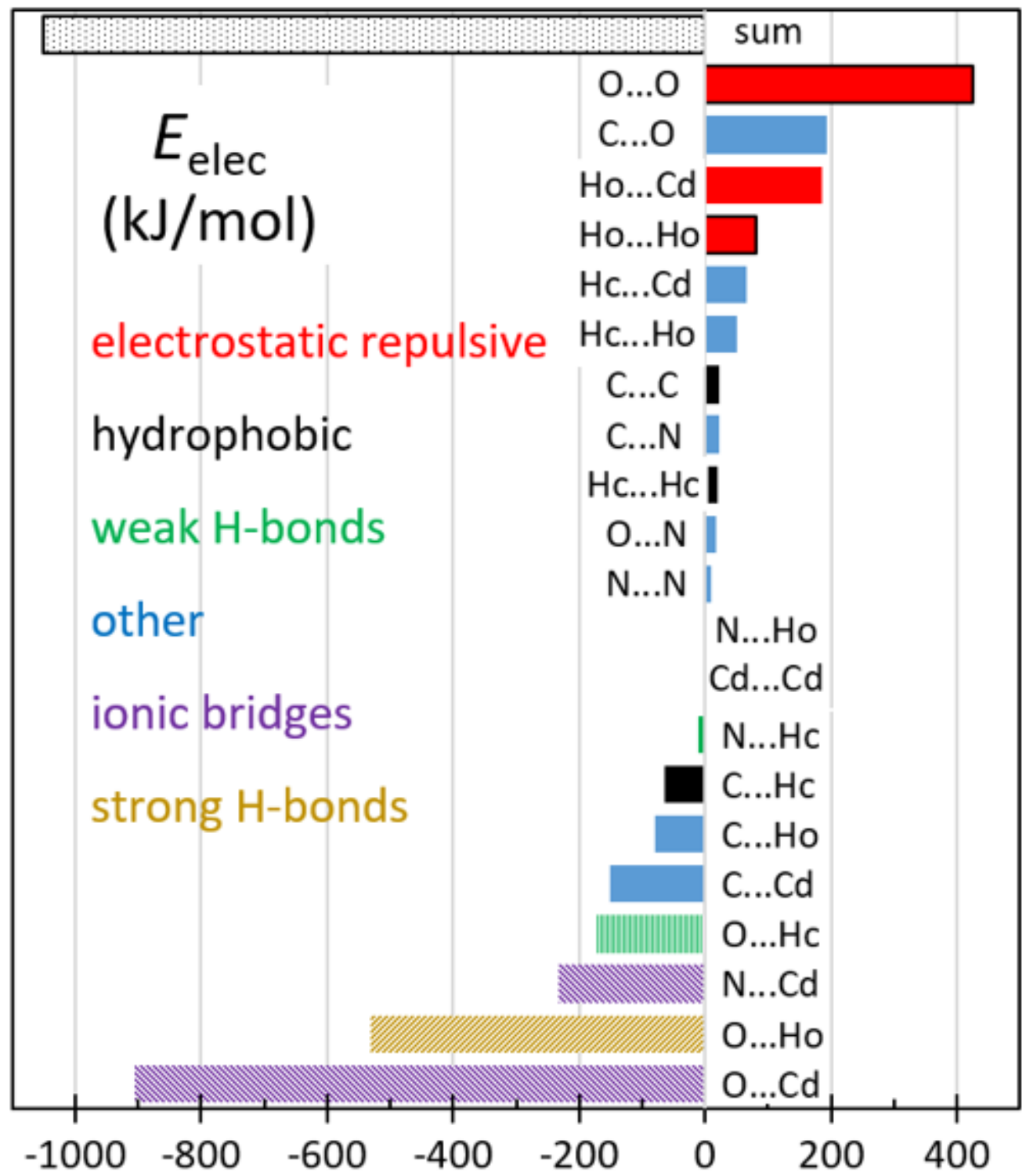

Figure 6

Electrostatic Energy of interactions within van der Waals distance plus $1 \AA$, decomposed into contact atom types. 


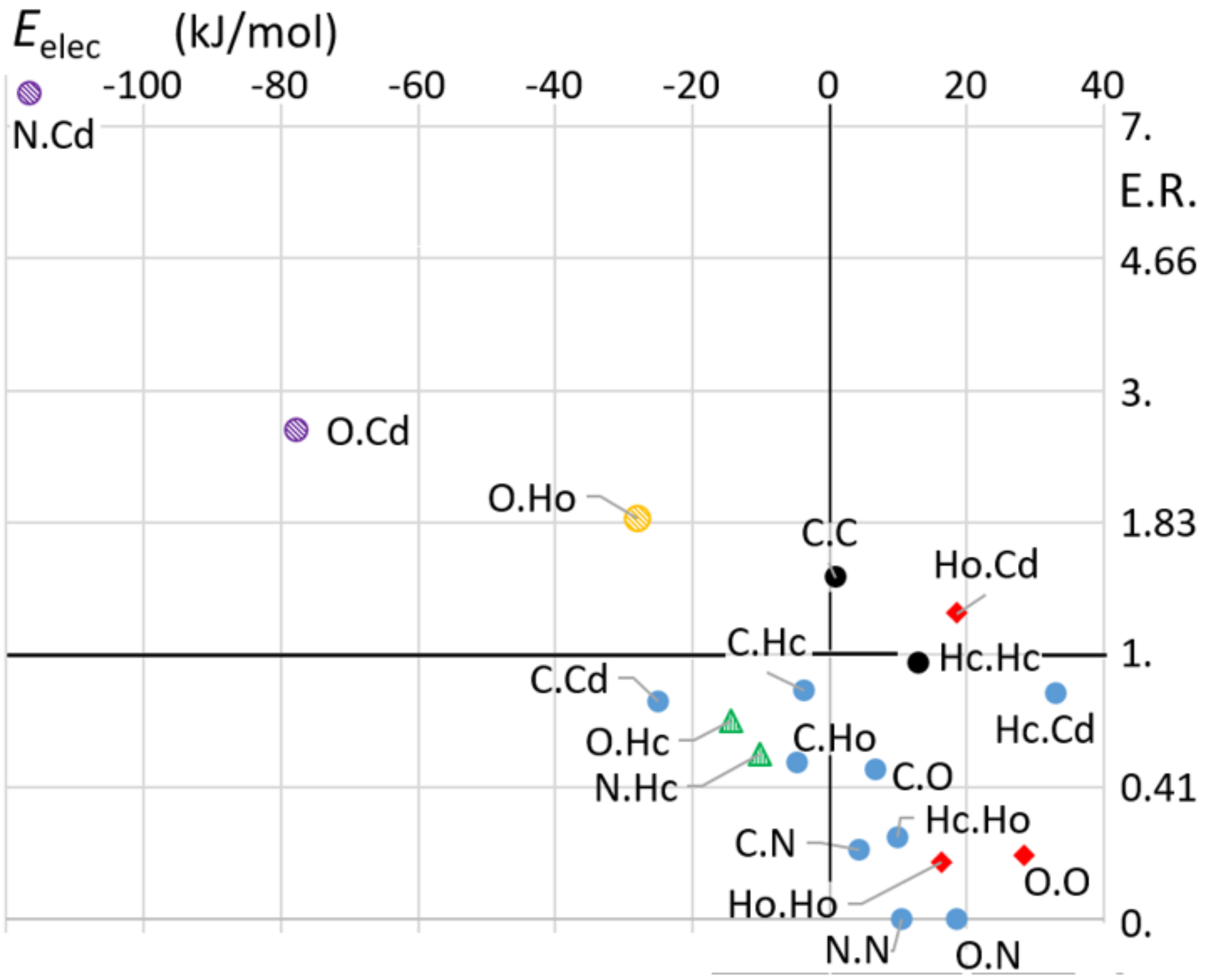

Figure 7

Scatterplot of the average Electrostatic Energy of existing contact types (within $1 \AA$ of van der Waals distance) and the Enrichment Ratio (E.R.). The coloring of contact types is as in Fig.6. 


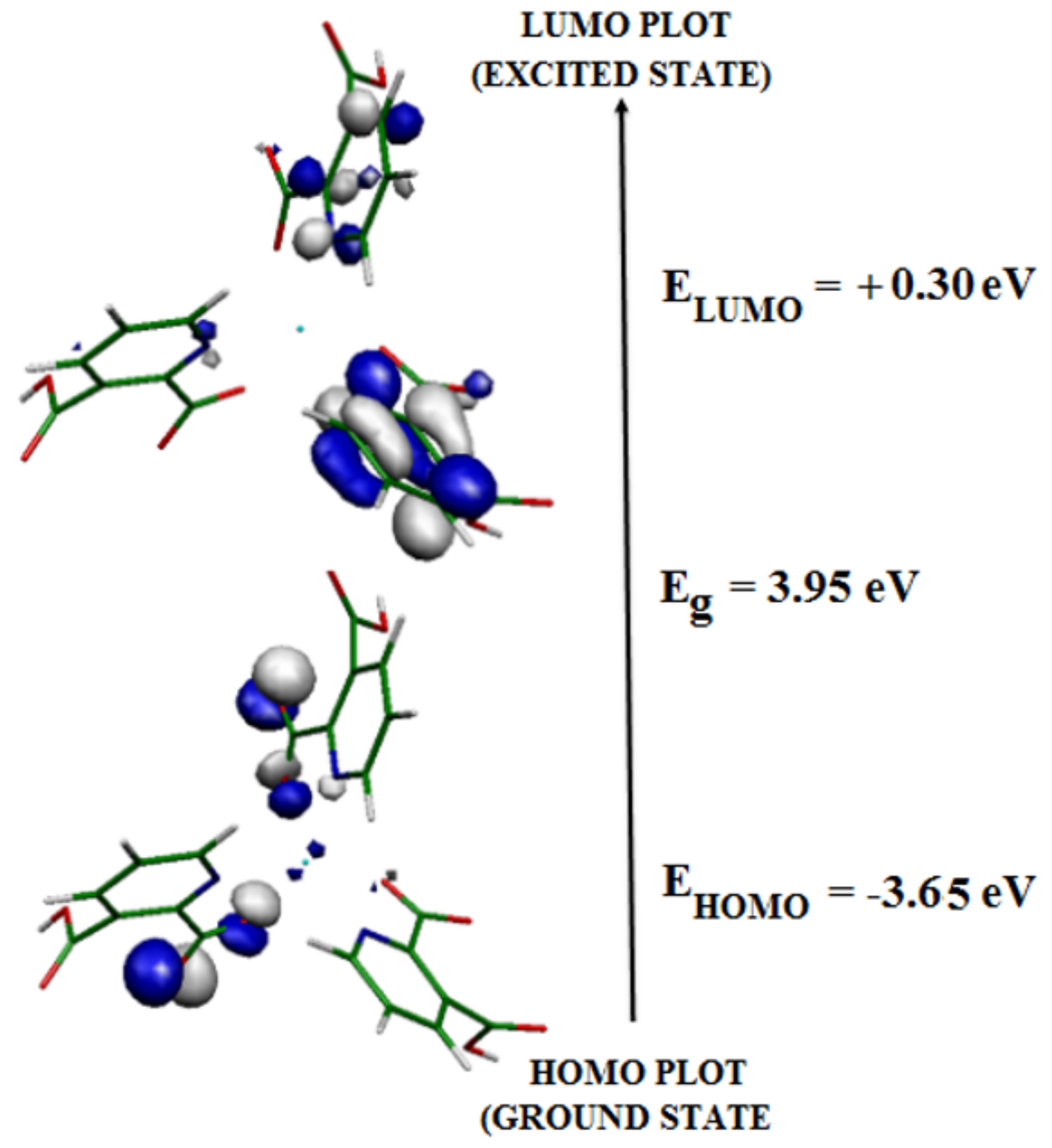

Figure 8

Frontier molecular orbitals (HOMO and LUMO) of the title compound. 


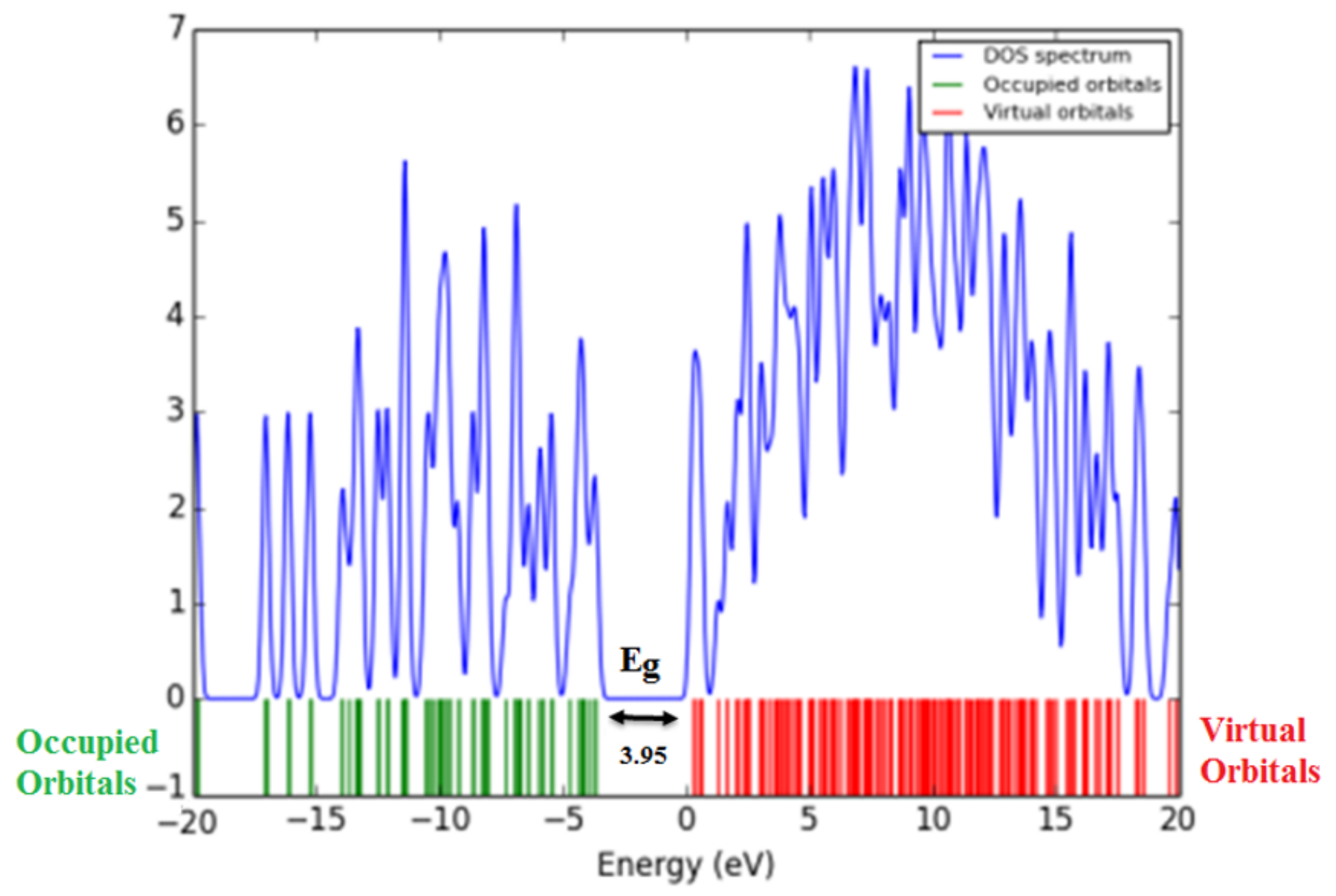

Figure 9

DOS spectrum and energy levels of the Frontier Molecular Orbitals.
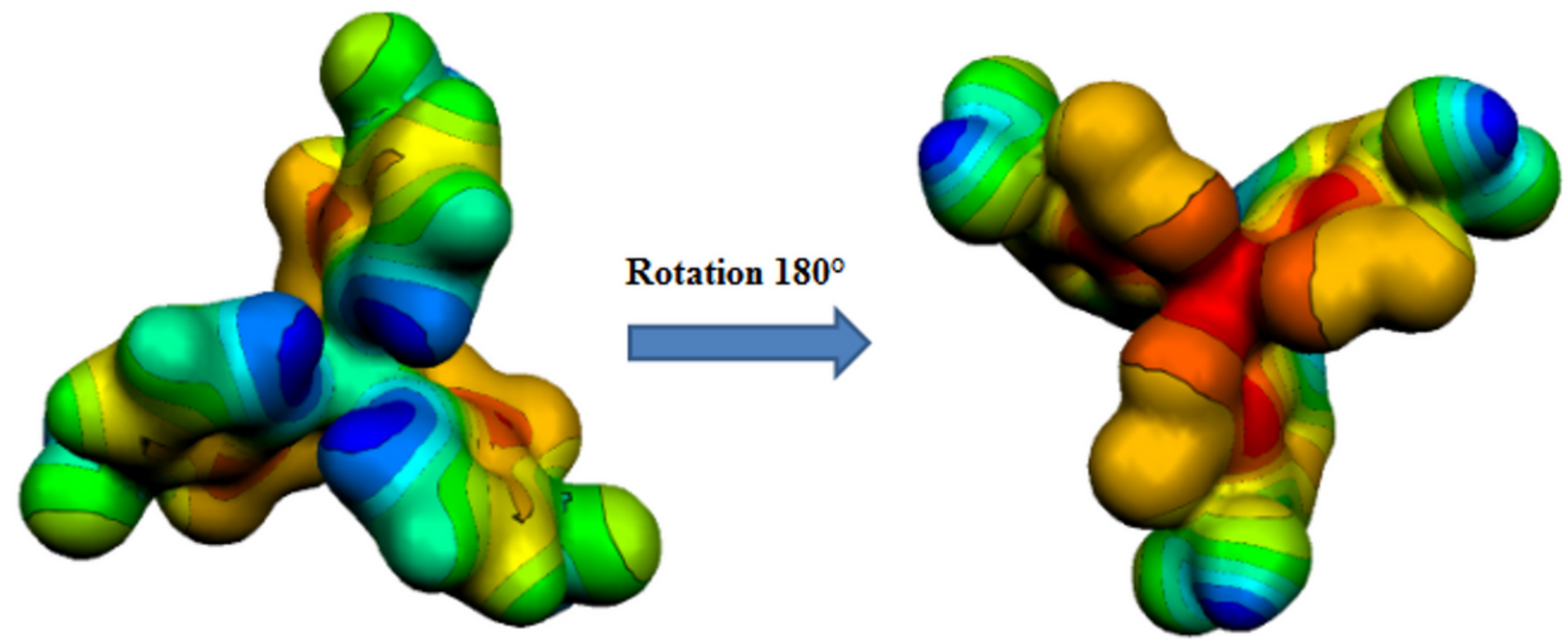

Figure 10 
Molecular electrostatic potential (MEP) of the title compound.

Page 22/22 